\title{
CAUTION AND CONSENSUS IN AMERICAN BUSINESS MEETINGS
}

\author{
Christina Wasson
}

\begin{abstract}
This article contributes to studies of politeness and talk in the workplace. In particular, it focuses on the ways in which cautiousness is exercised to achieve consensus in American business meetings. This topic is elaborated against the real-world background of the surveillance culture of corporate America and a tradition of consensus-oriented decision-making, in the theoretical context of politeness theory (adding variables related to the 'political economy' of the investigated interactions), and with the methodological insights provided by conversation analysis. 'Reversals' are identified as specific turn patterns in face-saving strategies aimed at consensus. Two processes are highlighted: Attempts at protecting oneself through a reversal of opinion, and protecting others by helping them articulate a reversal.
\end{abstract}

Keywords: Politeness, Caution, Consensus, Business Meetings, Talk in the Workplace

\section{1. "Politeness" in the political context of the workplace ${ }^{1}$}

In recent years, scholars of language use have evinced a growing concern with the question of how everyday talk is embedded in institutionalized structures of power. Collections and review articles have been published on topics such as language and political economy (Gal 1989), linguistic ideologies (Kroskrity et al. 1992; Schieffelin et al. 1998; Woolard and Schieffelin 1994), language in the public sphere (Gal and Woolard 1995), talk and violence in institutional contexts (Briggs 1997b), and the impact of globalizing forces on local language communities (Silverstein 1998). The emergence of critical discourse analysis can also be read as a response to this concern (Caldas-Coulthard and Coulthard 1996; Fairclough 1989; Wodak 1989). All of these efforts to situate language-in-use within its macrolevel context reflect both an increasing engagement among scholars with matters of public concern, and a growing sense that setting the boundaries of analysis at the borders

${ }^{1}$ This paper had its origins in a presentation made to the University of Chicago Language and Society Workshop. I would like to thank members of the workshop for their helpful comments. The discussion of surveillance was also furthered by my participation in a panel at the 1998 American Anthropological Association meetings on "Meetings in Context: Metadiscourse, Genre and Social Action" - my thanks to fellow panelists and audience members for their useful feedback (Wasson 1998). In addition, the paper has been strengthened by the thoughtful comments of an anonymous reviewer. Finally, I have consistently benefited from conversations with Eve Pinsker and Laura Miller. 
of a speech event is theoretically insufficient, since not all factors needed for an adequate interpretation are visible in the interaction itself (cf. Briggs 1997a).

In this essay, I join such efforts and concerns with respect to two bodies of research. One concerns a particular type of setting: The workplace. The other focuses on a particular type of interactional practice: Politeness.

In the last decade, a number of collections appeared that focused on talk in the workplace (Boden 1994; Button 1992; Drew and Heritage 1992b; Engeström and Middleton 1996; Sarangi and Roberts 1999b). The first volumes were framed in the research paradigms of Conversation Analysis and ethnomethodology. Such an approach brought a number of important strengths to these studies. Most significantly, perhaps, the question of how work practices are collaboratively accomplished on a moment-to-moment basis was explored for the first time. After all, face-to-face interactions constitute a central component of many kinds of work. As Suchman has pointed out in an essay titled "Making Work Visible," the lack of knowledge about how employees actually do their work "is particularly remarkable given the large and growing body of literature dedicated to workflow modeling, business process reengineering, and other methods aimed at representing work" in management studies (1995: 56). The use of Conversation Analysis (CA) facilitated the discovery of particular sequential patterns, types of turns, and participation frameworks in workplace interactions. Drew and Heritage provide a useful summary of such findings (1992a: 28ff).

At the same time, the reliance on CA limited the studies in certain ways as well. The CA stance that any contextual features that are salient to an encounter will be visible in the organization of the interaction itself kept the focus of much early research firmly at the microlevel. Some of the aspects of context that were often explored only superficially, if at all, were: The culture and history of the organization; the personal histories of participants, their relationships, and their political goals; the role of industry-wide patterns and management trends; and the ethnic and national cultures of participants and the field site. Such limitations were most pronounced in the first collection, edited by Drew and Heritage (1992). The second volume, edited by Button (1992), included several chapters that more thoroughly situated interactions in their organizational, professional, or historical context (especially those by Benson, Button and Harper, Jordan and Lynch). In the third study, Boden set forth micro-macro linkage as a worthy goal, citing the work of Giddens and Bourdieu as models (1994). However, she did not provide any extended examples from her own research.

The fourth volume, edited by Engeström and Middleton, shifted from CA to Vygotskian activity theory as its primary research paradigm (1996). As with the CA-based studies, careful and nuanced examinations of workplace interactions formed the hearts of the chapters. The context beyond the transcripts was considered to variable degrees. The chapters by Bødker and Grønbæk, Engeström, Mukerji, and Shaiken were quite thorough in this regard.

The most recent collection, edited by Sarangi and Roberts, explicitly strove to connect the interaction order with the institutional order (1999b). In the introduction, the editors provided a detailed discussion of the tendency for sociolinguistic studies of the workplace to neglect institutional concerns, while other sociological studies have paid little attention to interactional patterns. The editors not only argued for an exploration of the dynamic between these two orders, but also expanded the consideration of macrolevel 
issues to include "shifting power relations with the state machinery and the way in which the professions are implicated" (1999a: 8).

In this paper, I continue the effort to situate the interaction order in its organizational context. I describe particular turn types and interactional sequences, using insights from other CA-based studies of work. But I also consider how the habitus of the participants who choose such conversational moves is shaped by their lived experience as managers and professionals in an American corporation. In addition, my focus on the private sector helps redress the relative paucity of studies in this domain. The five volumes just described included only eight examinations of business settings, out of a total of 45 papers that investigated a particular site; and four of those eight were in the Button collection and focused specifically on technology issues.

The other body of research that I seek to build on is the literature on politeness. More than one colleague, on seeing the transcript examples presented in this paper, quickly classified the material as instances of politeness. At first, this surprised me, since Brown and Levinson's model was quite different from local community members' understandings of their interactional practices. On reflection, however, I believe that the politeness paradigm can help illuminate the data I present. But one important component must be added: The talk must be grounded more carefully in its political surround (Watts 1992). For a study of corporate managers and professionals, this means exploring the way the power of the organization shapes workplace interactions.

Brown and Levinson, of course, initiated the first wave of contemporary research on politeness by identifying recurrent patterns in widely diverging languages (1987). Their claim to have discovered pragmatic universals gave their study great theoretical force but also opened it up to critique. A second, post-Brown and Levinson wave of research addressed some of the primary limitations of the original work by highlighting the importance of culture in shaping local linguistic understandings and practices (e.g. Kienpointner 1999; Mao 1994; Watts et al. 1992). Authors working in this vein identified profound cultural differences in the notion of face, problematizing Brown and Levinson's claim to have produced a universal model based on a pan-human sense of face. The Western individualism underlying the rational actor conception of a "Model Person" was pointed out again and again.

In their emphasis on cultural difference, however, participants in this second wave of research adopted a notion of culture which was rather problematic. First of all, such studies tended to reify and homogenize cultures, portraying them as bounded entities whose members all adhered to the same values and beliefs. As Eelen pointed out, "culture' has received various... definitions... Whatever their specific definition, however, the results reported in such research are always said to pertain to the whole of the group under investigation" (999: 169). In such studies, a monolithic set of attitudes and ideologies was ascribed to each group, and these sets were then compared and contrasted with each other. Contradictory attitudes within a group were rarely explored.

Furthermore, cultures were largely equated with values. The social structures, everyday practices, and material constraints which shaped the lived experience of members of these groups were at best briefly alluded to. In such research, conversational examples were - and are - often taken from casual interactions between friends, where the exercise of institutional power is least evident. In other cases, authors background the organizational constraints that shape particular interactions by presenting a collection of 
unrelated examples from disparate settings.

A third wave of politeness studies that addresses these concerns is starting to appear. For instance, Eelen has critiqued the assumptions that "culture" is shared by all members of a social group, and that it is a sharply bounded entity (1999). Miller and Okamoto have explored differences between the ideology and actual use of politeness forms in Japanese, highlighting the importance of situational and class factors (Miller 1989; Okamoto 1999). Watts has documented the historical development of British notions of politeness in their specific social and political settings (1999).

This essay contributes to the third wave of research by situating a particular form of "polite" talk in its organizational context. The setting is corporate America. I examine how decision-making practices among managers and professionals are shaped by the political exigencies of their work life. Indeed, corporations offer a type of field site where connections between power structures and the actions of those who navigate within them are particularly evident. Employees themselves comment on these connections. Below, I describe the sense of surveillance that managers and professionals feel in many of their work settings, and how that sense shapes their interactions. Consensus decision-making practices on teams are presented as an illustration; the analysis builds on previous research into business negotiations (Ehlich and Wagner 1995; Firth 1995).

The findings in this paper come from sixteen months of ethnographic and linguistic fieldwork at Sigma Corporation, ${ }^{2}$ a large high-technology company based in the United States. From 1992 to 1994 I engaged in full-time participant observation of employees' everyday work activities there. I made audio recordings of a variety of meeting settings, and maintained extensive fieldnotes. The paper focuses on employees at one of the four facilities I examined. This was a largely white collar site, the administrative headquarters and design center for one of Sigma's businesses. About 750 employees worked there. The considerable majority were engineers; the rest were members of "support functions," the professions that help manage corporate infrastructures, such as human resources (personnel) and finance.

\section{Work settings in corporate America: The surveillance continuum}

For managers and professionals in corporate America, a key influence on their actions is the surveillance to which they are subjected (Wasson 2000; Goffman 1959; Kunda 1992). By using the term "surveillance," I am, of course, evoking Foucault; however, I wish to add a greater consideration of the production, reception, and circulation of talk to his original focus on visual technologies of observation and control (Foucault 1977; Briggs 1997a).

Organizations ultimately exert power over managers and professionals by controlling their career advancement (Kanter 1977; Rosenbaum 1984; Whyte 1956). While corporations maintain an ideology of objective meritocracy, underpinned by rationalized "performance reviews," employees recognize that promotions are closely linked to their socially constructed reputation (Jackall 1988; Ourousoff 1993). Managers and professionals are therefore highly sensitive to being scrutinized by those who might evaluate them. Their

\footnotetext{
${ }^{2}$ The name of the company is a pseudonym. The names of employees have also been changed in order to preserve their anonymity and confidentiality.
} 
superiors are those whose opinions matter in the end, since they are the ones who can offer or withhold promotions. However, corporate surveillance operates not only through direct observation, but through the circulation of reputations - the gossip that follows particular performances. Since anyone can recount an incident, the scrutiny of one's peers also matters. "From the point of view of the individual..., agents of control are everywhere: One is surrounded and constantly observed by members... who, in order to further their own interests, act as... enforcers of the organizational ideology" (Kunda 1992: 155). Such a sense of being surrounded by potential observers resonates with Foucault's comments about surveillance in $18^{\text {th }}$ and $19^{\text {th }}$ century schools, factories, and prisons, where, "although surveillance rests on individuals, its functioning is that of a network of relations from top to bottom, but also to a certain extent from bottom to top and laterally" (1977: 176). Similarly, Foucault notes that the French Revolution developed a new concept of justice in which citizens' behavior was regulated not by punishment so much as by 'immersing people in a field of total visibility where the opinion, observation and discourse of others would restrain them from harmful acts" (1980: 153).

What Foucault did not consider, however, was that even in the most complete institutions, such as prisons, the level of surveillance could be considerably mitigated. For instance, a guard who felt friendly towards an inmate might choose to overlook his transgressions. At Sigma Corporation, I found that the level of surveillance to which an employee felt subjected could be thought of as occupying some point on a continuum. This point was partly presupposed by the context, and partly negotiated by participants in the interaction.

It was presupposed by three aspects of the situation. One was the power distance between employees and their interlocutors - the degree to which the interlocutors were senior to the speakers in the organizational hierarchy. A second aspect of the context was the social distance between speakers and their interlocutors. Such peer surveillance was the most powerful between relative strangers, or employees who were rivals or disliked each other. Friends and allies could trust each other not to spread damaging stories about one another. A third contextual dimension was the formality of a given event. The more structured the sequential ordering of speech activities was, the more speakers presented rehearsed reports instead of talking spontaneously, the more participants evinced a sense of being under surveillance. These three presupposed elements of context could shift independently of each other, but they often changed in tandem.

At the same time, participants in an interaction also strove to reduce their sense of mutual surveillance. They did this by displaying friendliness and trustworthiness toward one another. This was especially effective between relative peers who did not know each other well, since social distance could be reduced through interpersonal negotiation in a way that organizationally determined hierarchical distance could not be.

\section{Quickly jettisoned opinions: Employees' disposition towards caution}

One of the teams I observed at Sigma Corporation was the Extra Recognition and Awards (or ERA) team. It arranged special rewards for individuals who had worked on projects outside of their regular responsibilities. At one point, the team decided to survey employees in order to obtain feedback about the ERA program. They collaboratively 
brainstormed a list of survey questions. Here is an example of one team member's suggestion and how it was received. ${ }^{3}$

(M07: 159-162)

1 Carol: How about just something straightforward,

2 do you like the ERA program.

$3 \quad(3.0)$

$4 \quad$ Or is that too scary a question.

5 They'll all be saying no,

$6 \quad$ we'll just close up shop.

Carol's suggested question, in line 2, invited a global critique of the program which was the team's raison d' être. After the rest of the meeting participants responded to her proposal with silence (line 3), she withdrew it (lines 4-6), distancing herself from the suggestion by humorously pointing out its riskiness: The team could be dissolved as a consequence! Carol's rapid change of opinion indicates that she interpreted the silence of other team members as a negative assessment. ${ }^{4}$ Notice that she abandoned her proposal as soon as she sensed that other team members might be finding something problematic in it. She did not try to hold on to her opinion by, for instance, waiting for someone else to articulate disagreement explicitly, and then countering the argument.

Carol's readiness to jettison her opinion is typical of the caution that managers and professionals exhibit in many situations. By "caution," I refer to a disposition to display conformism and speak with care in settings where speakers are concerned about the surveillance of their interlocutors. Employees enact this interactional posture through a variety of interrelated linguistic practices; not only through a readiness to change their point of view, but also through the extensive mitigation of negative assessments, the avoidance of metapragmatic commentary about disagreements while they are in progress, and so forth. A cautious disposition helps a speaker protect her reputation by preventing her from alienating other employees, or becoming associated with an unpopular point of view. More importantly, perhaps, it encourages a variety of behaviors which promote the interests of

${ }^{3}$ Transcription conventions are based on the Jefferson system (e.g. Sacks et al. 1974). The key features used here are:
$(())$
(3.2)
boldface double parentheses indicate transcriber's descriptions of talk numbers in parentheses indicate length of a silence, in seconds very short pause, of about a tenth of a second some form of emphasis, which may be signaled by changes in pitch and/or amplitude

: $\quad$ intervening utterances have been removed
$=\quad$ latching together of two phrases or sentences
- $\quad$ word or sound is cut off
, falling-rising intonation, characteristic of e.g. items in a list
"sentence-final" type of falling intonation at end of phrase rising intonation at end of phrase intonation of surprise or forcefulness at end of phrase

\footnotetext{
${ }^{4}$ Numerous articles have argued that participants in an interaction often interpret silence following a suggestion as a negative assessment. In the conversation analysis literature, such silences are treated as "predisagreements," a common form of mitigation (Davidson 1984; Pomerantz 1984; Sacks 1987).
} 
the corporation. For instance, employees seek to display alignment with corporate ideology and the interests of senior managers. They demonstrate their ability to be "team players" by establishing good relationships with other team members, often by being agreeable and flexible.

The caution and conformism that corporate settings tend to inculcate were first described and critiqued in a spate of literature that appeared in the 1950s (Dalton 1959; Mills 1951; Riesman 1950; Whyte 1956). In more recent years, managerial caution has been downplayed in mainstream organizational research, perhaps because it has become naturalized by the passage of time. It continues to surface, however, in the occasional corporate ethnography that is published (Jackall 1988; Kanter 1977; Kunda 1992). Carol's willingness to abandon her suggestion in example (1) is, therefore, a manifestation of a historically enduring managerial disposition.

Employees at Sigma Corporation most often engaged in metapragmatic discourse about caution by joking about the dangers of its opposite: Outspokenness. Sometimes they drew on a metaphor in which the act of talking stood for the articulation of controversial opinions. For instance, the organizer of the ERA team, Anne, told the rest of the team a humorous story about how they had acquired a new member, Bill.

\begin{tabular}{|c|c|c|}
\hline \multicolumn{3}{|c|}{ (M05: 37-44) } \\
\hline 1 & Anne: & Bill was funny because \\
\hline 2 & & we had had a nomination form from him \\
\hline 3 & & if you recall?= \\
\hline 4 & & $=$ I don't know if \\
\hline 5 & & but uh- \\
\hline 6 & & In the last couple of meetings \\
\hline 7 & & we've been going around and around with him \\
\hline 8 & & and so then when I told him that, \\
\hline 9 & & we had expanded the team and David- \\
\hline 10 & & and that heh he was on it \\
\hline 11 & & he goes, \\
\hline 12 & & what does it mean \\
\hline 13 & & if you like cause a little commotion \\
\hline 14 & & you hah have to be hohon the team?= \\
\hline 15 & & I said exactly, \\
\hline 16 & & you spoke too loudly. \\
\hline
\end{tabular}

Bill had a reputation for stubbornly holding on to his views, and, thus, being hard to work with. Long before I met him, I had heard people refer to him as "difficult." Here Anne alluded to an episode where Bill had complained persistently and at length to the ERA team that the award they had given one of his employees was too small (lines 2-7). But Bill paid for not quickly aligning himself with the views of others. Some weeks later, when attrition led Anne to approach senior managers for some new team members, Bill's boss, David, immediately suggested him (lines 9-10). According to Anne, Bill constructed his selection as a punishment (lines 11-14). In the punch line of her story, Anne articulated the "talk stands for controversial opinions" metaphor by saying that Bill "spoke too loudly" (line 16). Here she emphasized his stubbornness and willingness to argue by highlighting 
the "noisiness" of his metaphorical talk.

Another example of the metaphor was voiced by Bill, in reference to himself, after he had joined the group. It was Bill's suggestion for the ERA team to conduct the employee survey mentioned in example (1). On the day the team began to design the survey, Anne reminded meeting participants whose idea it had been. Bill responded by saying jokingly:

(3) (M07: 59)

1 Bill: I (.) know,

$2 \quad$ I opened my mouth.

In this passage, Bill simultaneously acknowledged his reputation for being opinionated, and the irritation he risked from other employees. After all, the survey not only required time and effort from all ERA team members, but created a danger that the team might receive negative evaluations.

Both of these examples show that the disposition toward caution was not uniformly distributed among employees. Although the people who worked at Sigma were subjected to a shared set of organizational pressures, they responded in variable ways; some individuals were more cautious than others. Thus, when I examined consensus decisionmaking practices on teams, it became clear that certain team members held on to their opinions rather more vigorously than the rest. Such consensus resisters exerted a disproportionate influence on decision outcomes, since other meeting participants were generally quite flexible in their opinions.

Although Bill sometimes displayed high levels of caution, he often resisted consensus. For example, in one meeting he strongly criticized an award application that had been highly evaluated by the rest of the team. The employee nominated by this application had devised a more efficient process for procuring business cards for employees. The new process cut out a great deal of red tape. According to the application, which Anne, the organizer, read out loud and displayed on the overhead projector, this process was "estimated by Graphic Arts and Purchasing to save approximately $\$ 25,000$ per year in administrative costs." Faced with such an impressive number, and a glowing written recommendation, the immediate response of most team members was highly positive.

(4) (M05: 607-615)

$\begin{array}{lll}1 & \text { Ellen: } & \text { I mean it really is } \\ 2 & & \text { a tremendous savings } \\ 3 & \text { Anne: } & \text { That it never was thohought of before! } \\ 4 & \text { Rick: } & \text { And it is, it is a real big one, too } \\ 5 & \text { Ellen: } & \text { Oh God, } \\ 6 & & \text { yeah } \\ 7 & \text { Rick: } & \text { It's a real big one. } \\ 8 & & \text { Good idea. }\end{array}$


After this extended paean to the nominee, one team member suggested a generous award amount which seemed to receive a general consensus. Moments later, however, Bill broke in with a series of powerfully phrased negative assessments.

(M05: 704-719)

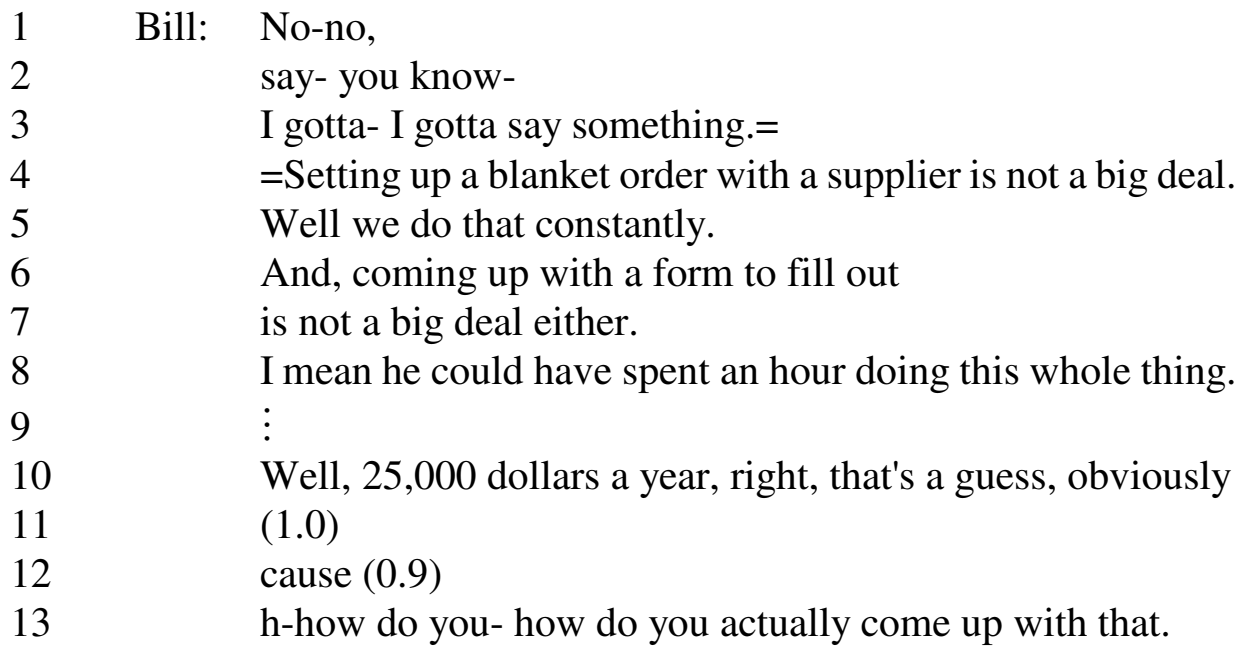

In these passages, Bill threw ice water on the admiration society which had been developing for the nominee. Even his first phrase, a double "no," revealed a marked lack of caution and resistance towards consensus (line 1). Next he referred to his outspokenness, drawing on the "talk stands for controversial opinions" metaphor (line 3). This statement framed the criticisms of the application which Bill subsequently offered. He repeatedly argued that the project was "not a big deal" (lines 4-7), and said that the nominee might have spent only an hour on it (line 8). In addition, he questioned the accuracy of the claimed savings amount (lines 10-13). Bill's oppositional stance led to an extended discussion between him and the rest of the meeting participants. Eventually, they settled on an award amount that was only about half of the original suggestion.

As this example shows, outspoken employees could sometimes exert a great deal of influence over decision outcomes. However, individuals who were markedly less cautious than the norm also brought risks upon themselves. As examples (2) and (3) revealed, Sigma employees shared a belief that there was often a price for speaking out, usually paid the speaker, sometimes borne by others. Such a perception is, indeed, supported by ethnographic observations of this workplace, as well as of others (Jackall 1988; Kanter 1977; Kunda 1992). For instance, Bill's career had stalled - he had not received a promotion in a number of years - and his coworkers speculated whether it might be due to his "difficult" personality.

In another case I observed, a fast-rising manager named Maria made the mistake of questioning the fairness of Sigma's annual team competition before an affronted vice president. Having been on a team that failed to win, Maria jokingly suggested that she would form a team for next year's competition "to look at ways to improve the judging process." The story of her unwise comments circulated widely. She was taken to task by her boss and her boss's boss. The head of human resources started to use Maria as a symbol of employees with a bad attitude. Maria not only stopped receiving promotions, 
but was reassigned to a less prestigious position. Her own analysis of these events was that she had always been "too frank for my own good."

In a third situation, Jim, a manager who had long been known as blunt and outspoken, reached the level of vice president through his reputation for effective project management. ${ }^{5}$ However, at that point, Jim was refused further promotions because he lacked a "people side," as other managers put it. For example, he protested against a new program to improve employee treatment by saying, at a meeting of vice presidents, "does this mean I have to kiss their ass?" A senior manager with whom I discussed the situation said, "Jim will state very openly that he hates any of what he calls the soft stuff. That has been okay up until this level, but it's starting to hurt him. He is being told now that he needs to grow in that area in order to rise further." Although this criticism was stated in terms of Jim's lack of a "people side," it can also be interpreted as a comment about his excessive bluntness. Most vice presidents agreed with Jim's perception of the new program. Yet they were more careful about saying so. Jim's willingness to go on record with memorable phrases which were critical of corporate programs was more unusual - and a political Achilles' heel.

Although stories such as these circulated frequently at Sigma, employees did not, by and large, devote much thought to their cautiousness in the hyper-reflexive manner so prized by Homo scholasticus (Bourdieu 1990). In most situations where caution was the interactional norm, it was simply taken for granted. In such settings, participants automatically avoided the extreme view, the irresoluble conflict. Meetings appeared to be relatively placid and uneventful. At worst, they seemed boring. Yet I would argue that their very uneventfulness was in fact a carefully wrought achievement.

\section{Consensus decision-making in team meetings}

In order to illustrate the disposition toward caution that managers and professionals often evince, I will explore the decision-making practices of cross-functional teams at Sigma Corporation. During such activities, participants displayed a particularly high level of caution.

"Cross-functional" teams drew their membership from across the organization. Their composition was understood to signify that the team in some sense represented the facility as a whole. Their projects thus dealt with matters that potentially affected most, or all, employees. At the same time, their tasks were not usually of critical importance, since senior managers supervised such issues personally. The teams' goals were not closely related to most participants' primary work activities; few team decisions had the potential to threaten their individual careers. This enabled team members to be particularly flexible in their opinions. Furthermore, because they did not work together on a daily basis, team members might rarely see each other outside of team meetings, which usually did not occur more than once a week, and often less frequently. This comparative lack of familiarity between participants meant that they had a certain sense of being under surveillance from

\footnotetext{
5 "Vice president" was a senior middle management category at Sigma. There were about 250 vice presidents across the corporation.
} 
one another. They did not know each other well enough to be fully open and relaxed in their conversation.

Most of the examples in this paper are taken from the meetings of one crossfunctional team: The Extra Recognition and Awards (ERA) team. This group met every two weeks. The primary activity during meetings was the evaluation of applications for awards. The organizer of the team, Anne, was a lower level manager in the compensation department.

An ideology of consensus decision-making prevailed in cross-functional team meetings. This ideology involved the notion of equal voice for all participants, and the principle that everyone should subscribe to the final decision. It was described in the following way in a team training manual prepared for Sigma:

all members have the opportunity to participate in the discussion, to ask questions and give opinions... the entire group arrives at a decision... no averaging, majority-rule voting, or horsetrading (Balholm, Field and Associates 1992).

The value placed on consensus and equality in these meetings meant that aggressive, domineering behavior was interpreted negatively. There was no way for participants to enhance their reputation by displaying the kind of confrontational style that in other contexts might be positively interpreted as showing "leadership." Consequently, the main source of symbolic profit for participants in these meetings was to develop a reputation as a good team player, and to build their alliances with each other. Of course, it was always possible for them to damage their reputation, by strongly voicing an opinion that alienated other meeting participants, or that provided fodder for damaging gossip. Team members were therefore oriented not only toward accumulating social and symbolic capital in these meetings, but perhaps more importantly, toward preventing its loss.

\section{Collaboratively accomplishing reversals of opinion}

In cross-functional team meetings at Sigma, participants' disposition toward caution was perhaps most evident in their tendency to display mutual alignment, to adhere to the same views (cf. Firth 1991: 145; Francis 1995: 41). Of course, the very notion of consensus decision-making demanded that team members work towards a unity of perspectives when differences arose between them. However, there are many styles of expressing and resolving disagreement, from Schiffrin's sociably disputatious Jewish couples in Philadelphia (1984), or the members of Schwartman's Midwestern community health center, where the process of reaching consensus was filled with "a great deal of emotion, expressions of conflict, crying, posturing, yelling, and so forth" (1989: 133-134), to crossfunctional team members at Sigma, whose interactional practices revealed a desire for conformity and a pervasive discomfort with disagreement. Each conflict that arose could be seen as a microlevel drama of rupture in the participants' mutual alignment, and its subsequent repair.

Decision-making processes in institutional settings have been explored by numerous scholars, from a broad range of disciplines, under the heading of "negotiation." Of most relevance to the current discussion is the work of a group of CA-influenced sociolinguists (Ehlich and Wagner 1995; Firth 1995; Maynard 1984). By taking naturally occurring 
discourse as their object of investigation, they have been able to identify a number of recurrent patterns in the construction of decision-making activities. My discussion builds on their findings.

In simplest structural terms, the decision-making activities that I observed on crossfunctional teams were sequences that began with some team member articulating a proposal, continued with evaluations from other team members, and ended when a consensus decision was reached. There are no examples in my data of issues that did not end in consensus, outside of a few decisions that were postponed in order to consult with other employees, and none of these had engendered lengthy or difficult discussions.

A basic building block of the decision-making activities was the type of adjacency pair termed a "bargaining sequence" in the literature on negotiations.

1. A first speaker proffers a proposal or position-report

2. A second speaker evaluates the previous turn positively or negatively by displaying "alignment or nonalignment with the initially exhibited position" (Maynard 1984: 78).

At Sigma as in other institutional settings, these sequences were regularly "elaborated and extended in various ways," and each turn could take multiple forms (Francis 1995: 1). For instance, proposals could be constructed as suggestions, requests, or "musings." Furthermore, proposals were not defined solely by the intentionality of the speaker, but rather also "post hoc" by the actions of others (cf. Duranti 1992; Hill and Irvine 1992). Team members could construct an utterance as a proposal simply by responding with a positive or negative assessment of its content. In a crucial way, then, it was some participant's evaluation of a preceding utterance that signaled to the meeting as a whole that a decision making activity was underway. In particular, negative assessments of a proposal - expressions of disagreement - demanded further efforts from participants. In such situations, at least one team member had to change her opinion in order for consensus to be achieved.

\subsection{Protecting oneself through a reversal of opinion}

One sign of meeting participants' disposition towards caution was their readiness to abandon their opinions. This behavior was reviewed broadly in Section 3; I turn here to a more detailed exploration of the phenomenon in the context of consensus decisions. In my observations of cross-functional team meetings, participants whose proposals were negatively evaluated immediately abandoned their position in the majority of cases. Faced with disagreement, they responded by uttering a statement that embodied the opposite view of the one they had expressed only moments before. For convenience, I will refer to such statements as "reversals." Reversals displayed the speaker's decision not to contest the negative evaluation of her suggestion, but rather to ratify the contrastive position taken by other participants in the interaction. By abandoning their original viewpoint, such speakers reinstantiated the group's preferred state of mutual alignment, and accomplished a consensus decision. 
In addition, uttering a reversal enabled speakers to shed their association with the position they had expressed previously. Henceforth they would not be held responsible for a view that - based on the opposition it had encountered - might turn out to be a political liability. Displaying inconsistent opinions was never a source of criticism in crossfunctional team meetings. On the contrary, by articulating reversals, meeting participants protected their face, their reputation, their symbolic capital.

Although moves of this type have been identified in the negotiation literature that focuses on business settings, they have not received much attention. ${ }^{6}$ This may be because most prior research has examined interactions between members of different corporations, such as sales negotiations, where the parties were more attached to their positions than in the situations examined here.

The readiness of cross-functional team members to jettison their opinions can be seen in the efficacy of silence as a negative assessment (Davidson 1984; Pomerantz 1984; Sacks 1987). The type of interactional sequence illustrated by example (1) at the start of Section 3 was quite common: A suggestion followed by silence from other team members was often succeeded by an immediate reversal of opinion by the maker of the suggestion. Below is another instance of this pattern.

$\begin{array}{ll}\text { (M09: 116-118) } \\ 1 & \text { Anne: Why don't we } \\ 2 & (3.9) \\ 3 & \text { try to decide on an amount. } \\ 4 & (5.9) \\ 5 & \text { Or do you want to look at the rest of them too, } \\ 6 & \text { and get all these amounts together. }\end{array}$

Here Anne, the ERA team organizer, suggested that members try to decide on an award amount for an application she had just read to the group (lines 1-3). The silence in line 2 did not appear to signify disagreement for meeting participants; Anne did not respond to it as such, and anyhow, the phrase "why don't we" contains little of substance to disagree with. However, when Anne's completed suggestion was followed by a somewhat longer silence in line 4 , she abandoned her idea in favor of a new proposal. She broke the silence by suggesting that they first read through the rest of the applications on hand, and then decide on award amounts for the whole collection at once (lines 5-6). Anne's reversal indicates that she interpreted the silence in line 4 as a negative assessment. Furthermore, in saying "Or do you want to..." in line 5, Anne showed that she was trying to identify what it was that the other team members found problematic about her initial suggestion.

Anne's effort to bring her views into alignment with the rest of the group illustrates the pervasive, low-level concern meeting participants regularly exhibited regarding the reception of their suggestions. During most meetings at Sigma, a suggestion or proposal triggered its immediate evaluation: Either it was adopted as a basis for immediate action, or it was identified as problematic in some way. When a suggestion received a negative evaluation, the person who had proffered it could easily end up looking thoughtless,

\footnotetext{
${ }^{6}$ Maynard (1984) has explored such moves most carefully, in the context of plea bargaining.
} 
politically misguided, or even dumb. In settings where participants exerted surveillance over each other, the reputation of anyone who put forward a suggestion was, therefore, at risk. The vulnerability associated with proposals was, indeed, explicitly recognized by Sigma's management. The training manual for the company's course on teams admonished employees to be careful about criticizing each other: "People say things that stifle the free flow of ideas. This... limits creativity. We call this idea killing. Idea killers are any negative judgments made about a new idea" (Balholm, Field and Associates 1992). The inclusion of such a text in the training manual reveals an assumption that employees required special training in order not to engage in "idea killing."

\subsection{Protecting others by helping them articulate a reversal}

In my observations, I found that employees usually restricted their "idea killing" activities to certain kinds of settings, primarily either low surveillance encounters between wellknown coworkers, or high surveillance meetings in which, for various reasons, participants could profit from displaying a dominating, confrontational interactional style. "Idea killing" was not characteristic of cross-functional team meetings. On the contrary, participants in these interactions seemed highly sensitive to the vulnerability of individuals who offered suggestions. Far from harshly criticizing each other's ideas, they went to remarkable lengths to protect one another in situations of disagreement. Negative assessments were often constructed with tremendous delicacy and indirectness. Although their articulation created a rupture in participants' mutual alignment, such utterances also facilitated its repair, by gently pointing toward a less controversial viewpoint.

One of the main opportunities that cross-functional team meetings offered to participants was to extend their social networks. Acquiring broad alliances and friendships was, of course, essential to the long-term success of all managers and professionals. More immediately, developing relationships with other team members also helped reduce participants' concerns about being under mutual surveillance during their meetings. By demonstrating an attitude of concern and protectiveness toward each others' face and reputations, team members signalled their good will and effort to build trust.

A common way for meeting participants to signal good will to each other was to help one another avoid association with unpopular or problematic viewpoints. The least damaging way for an individual to articulate a reversal was for her to appear to change her opinion on her own. Other team members, could, however, help her in this process by delicately hinting that they regarded the suggestion as problematic; by giving her the opportunity to articulate a different opinion without having been obviously corrected; and by downplaying the fact that any change of opinion had even taken place. In these meetings, no one ever said, "but you just said the opposite a moment ago!"

Two kinds of interactional moves were particularly frequent in team members' efforts to help their fellows articulate reversals. One was the negative assessments through which they communicated their disagreement (C. Goodwin 1986; Goodwin and Goodwin 1992). These evaluations were characterized by a marked preference for agreement (Davidson 1984; M.H. Goodwin 1982, 1983, 1990; Pomerantz 1984; Sacks 1987; Schegloff et al. 1977). The most common forms of mitigation used by speakers included 
delaying expressions of disagreement; downplaying their knowledge or certainty; including agreement components with the disagreement; joking; and allusion.

Negative assessments were often followed by "choral responses" or "choruses" (Kangasharju 1996; Lerner 1993; Schegloff 1995). Such moves consisted of one or more agreement tokens, either brief expressions such as "yeah" or "right," or the repetition of words from the utterance being echoed. When a chorus was articulated by several speakers, they usually spoke simultaneously or in rapid succession. Kangasharju has argued that in multiparty disagreements, such moves are a primary means by which participants align themselves into conflicting camps (1996: 293-294). ${ }^{7}$ In the meetings examined here, a chorus following a negative assessment displayed the fact that a consensus opposed to the original suggestion was emerging among several meeting participants. It almost had the feeling tone of an invitation to the "outsider" to come and join the rest of the group.

Example (7) illustrates Sigma employees' use of negative assessments and choruses. At a more general level, the passage also reveals the caution that team members exhibited in criticizing each others' suggestions. This interaction was unusual in that the person whose idea was negatively evaluated repeatedly failed to grasp the alternative other participants kept trying to present. In most cases, team members were able to interpret each others' hints without difficulty. However, this particular failure led to an extraordinarily long sequence of negative assessments which highlighted the efforts team members were willing to expend in order to help the maker of a problematic proposal articulate a reversal.

This example comes from a meeting of the ERA team during which they developed an employee survey. The issue at stake was how to design survey questions that should be answered on a scale of one to... something. Anne, the organizer, started the discussion by asking how many points such scales usually have, suggesting four points as a possibility (lines 1-3). Although it might seem to the reader as though Anne herself were not particularly attached to the four-point scale proposal, the other team members oriented to this suggestion as one to which Anne's face had become attached. It gradually became apparent that the others preferred a five-point scale; but instead of saying so directly, they repeatedly made allusions to "the middle" of the scale in their negative assessments of the four-point proposal. Most of the corrective efforts were made by team members Bill and Eve.

(7) (M07: 183-197)

$\begin{array}{lll}1 & \text { Anne: } & \begin{array}{l}\text { Like four degrees? } \\ (1.1) \\ 2\end{array} \\ 3 & & \begin{array}{l}\text { How's that usually done. } \\ (6.9)\end{array} \\ 4 & & \text { Yeah, then you don't have (.) a middle, the- the } \\ 5 & \text { Bill: } & \text { middle } \\ 6 & & \text { Yeah } \\ 7 & \text { Mary: } & \text { Yeah } \\ 8 & \text { Deb: } & \text { Yeah, there's no middle of the roa(hh)d! } \\ 9 & \text { Eve: } & \text { With four degrees, you're pushing them } \\ 10 & \text { Bill: } & \end{array}$

\footnotetext{
${ }^{7}$ Research on multiparty disagreements often refers to opposing camps as "teams," a term which I avoid in this context since it would obviously be confusing (Lerner 1993; Kangasharju 1996).
} 


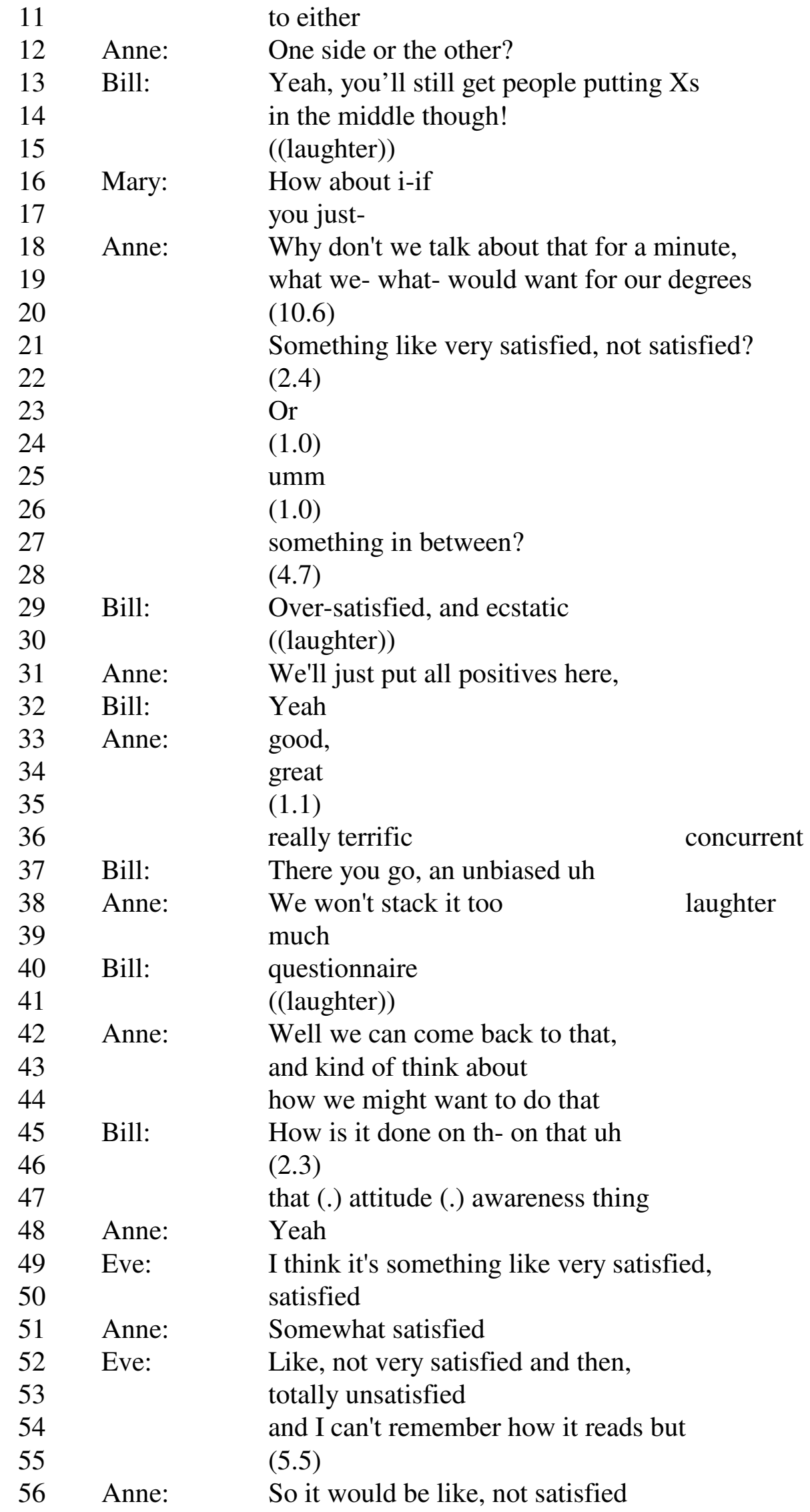


(2.5)

What'd you just say? You said something.

Eve: $\quad$ One is like a somewhat satisfied

which means I'm kind of $\mathrm{mmm}$

Anne:

somewhat satisfied

I don't know, what do you think

Eve: $\quad$ But I'm missing one, cause one is like very satisfied, and I don't know what the other one is, maybe it's a middle of the roa(hh)d one!

Anne:

Well we're not going to like, do all this today, get it totally perfect today

After Anne proffered her suggestion (lines 1-3), other team members responded with silence in line 4. As mentioned earlier, silences following a proposal were often interpreted by meeting participants as negative assessments. Here, however, Anne either did not interpret it that way, or chose not to respond to it. Bill broke the silence with a negative assessment, mitigating it prefacing it with an agreement token, "yeah." He also employed a certain degree of indirectness; rather than suggesting a 5-point scale, he gently pointed out what was problematic about a four-point scale: It lacked a midpoint (lines 5-6). Other team members immediately broke in with a chorus, three chiming "yeah," and one also echoing and completing Bill's last phrase (lines 7-9). Bill elaborated on his reasoning by saying that "you're pushing them to either" (lines 10-11), and at this juncture Anne appeared to grasp his criticism, since she completed his sentence, saying, "one side or the other" (line 12). Bill elaborated his argument one more time, using humor as a form of mitigation (lines 1314); his utterance elicited laughter from other meeting participants, and it might have seemed as though the sequence were concluded.

As the laughter died down, Mary started to say something (lines 16-17), but she was quickly interrupted by Anne and ceded the floor to her. Anne, in her turn, restarted the whole discussion by asking what meeting participants "would want for our degrees" (lines 18-19). Since they had just repeatedly tried to tell her that, it is not surprising that they responded with a rather lengthy, possibly baffled silence (line 20). Anne eventually ended the silence by tentatively suggesting a few terms (lines 21-27); her efforts petered out and there was another pause (line 28).

Subsequently Bill took the floor again. He often lightened tensions in decisionmaking discussions by initiating joking sequences, and did so here (lines 29-41). Anne collaborated in this activity, echoing his comments, and other team members joined in with their laughter. The whole sequence, with its overlaps and shared laughter, provided a respite from the team's misunderstandings and appeared to serve an affiliative function (Jefferson et al. 1987). I observed similar conversational detours in other situations of tension and unresolved disagreement.

At the end of the joking, Anne tried to end discussion of the 4-point question (lines 42-44). However, Bill immediately reopened the topic by asking how Sigma's annual 
employee survey handled the issue (lines 45-47). Anne then chorused his move, indicating that she accepted further discussion. In the next passage, Eve responded to Bill by constructing a plausible set of five survey question responses (lines 49-54). Interestingly, Anne helped Eve by herself articulating the response at the midpoint of the scale (line 51)! Yet she didn't seem to realize what she had done. After Eve finished talking, everyone was silent for a while (line 55), and when Anne spoke again, it was only to ask Eve for further clarification (lines 56-58). Eve seemed to have trouble reproducing her set of responses possibly mitigating her comments by downplaying her understanding of the issue - but concluded again with the need for a "middle of the road" response (lines 59-67). Another silence ensued, indicating Anne's lack of comprehension, and other team members' unwillingness to pursue this topic further (line 68). Eventually Anne broke the silence by closing the discussion (lines 69-71). She subsequently introduced a new topic. As a concluding remark, I should note that at the following meeting of the ERA team, Anne immediately spoke of a five-point scale when the subject arose again. It is quite possible that one of her fellow team members was able to speak to her more bluntly in private.

Example (7) was quite unusual with regard to Anne's failure to interpret other team members' negative assessments. In most cases at Sigma, team members quickly grasped the criticisms of others and reoriented themselves. Example (8) provides a more typical case in which a team collaboratively accomplished one member's reversal of opinion smoothly and rapidly. This sequence also illustrates the way meeting participants downplayed the fact that a change of opinion was even occurring.

In order to show the reader interactions from more than one cross-functional team at Sigma, I have selected this encounter from the meetings of a different group. The "team competition facilitators' team" organized their site's annual team competition. Meetings tended to revolve around concerns about how to attract teams to the competition; how to get senior management more involved; and with plans regarding the competition itself - the location, the selection and training of judges, and so forth. Team meetings took place approximately every two weeks, depending on need. The year in which I taped meetings, the organizer, Beth, was a mid-level manager from the management information systems function; for this team, the specialization of the organizer did not matter and varied from year to year.

At the meeting from which the passage was taken, participants were planning an upcoming training session that would prepare competitors for the next team competition. The discussion shown here started when the organizer, Beth, was asked by another member, Dave, whether whole teams should attend the training session, or only team leaders (lines 1-3). She proposed that only team leaders should attend (lines 4-5). The meeting group's subsequent negative evaluation of this proposal was accomplished over a number of turns, using a variety of forms of mitigation.

(8) (M06: 399-415)

$\begin{array}{lll}1 & \text { Dave: } & \text { Is that, the whole team goes or (.) just their, } \\ 2 & & \text { team leader. } \\ 3 & & \text { Each team leader } \\ 4 & \text { Beth: } & \text { We'll, } \\ 5 & & \text { we'll invite team leaders. }\end{array}$




$\begin{array}{lll}6 & \text { Dave: } & \text { OK } \\ 7 & \text { Jeff: } & \text { That one team is the Process Changers? } \\ 8 & \text { Beth: } & \text { Yes. } \\ 9 & \text { Jeff: } & \text { OK. } \\ 10 & \text { Beth: } & \text { And Pete Carter has been } \\ 11 & & (3.1) \\ 12 & & \text { been } \\ 13 & & (1.9) \\ 14 & & \text { very proud. } \\ 15 & & (2.7) \\ 16 & \text { Bob: } & \text { Just a- again it's a disc- I feel- } \\ 17 & & \text { oh I- I guess I would recommend } \\ 18 & & \text { that we don't limit the (.) } \\ 19 & & \text { the opportunity for training } \\ 20 & & \text { to the team leader } \\ 21 & & (1.3) \\ 22 & & \text { so that anybody that's interested, can just come } \\ 23 & \text { Dave: } & \text { ( }) \text { review, just a } \\ 24 & & \text { review of the first one } \\ 25 & & \text { to see whether } \\ 26 & \text { Beth: } & \text { Why don't we just invite teams } \\ 27 & & (1.3) \\ 28 & & \text { the first time. } \\ 29 & \text { Bob: } & \text { Invite teams, yeah. }\end{array}$

The initial response to Beth's proposal was an apparent agreement from Dave, "OK" (line 6). It is hard to know whether Dave was delaying disagreement or was genuinely in accord with the proposal at this point; his only other contribution to the assessment activity was a chorus after the negative assessment, considerably later in the sequence. After the "OK," a third speaker, Jeff, initiated a conversational detour by asking about the name of a team (line 7). Such detours were one of the ways meeting participants delayed articulation of a negative assessment.

Next, Beth, the maker of the proposal, started to elaborate on the detour, but no one took her up on this move (lines 10-14). The first possible completion point of her utterance, marked by a silence (line 11), was followed by two additional utterance components (line 12, line 14) demarcated by further silences (line13, line 15). As Davidson has pointed out, such "components occurring after a possible completion point may be providing the [speaker] with a monitor space in which he or she can examine what happens or what does not happen there for its acceptance/rejection implicativeness" (1984: 117). One can surmise from the way Beth's narrative trailed off that she was interpreting the emerging silence as signifying that her position was regarded as problematic by other participants.

After the pause in line 15, a fourth participant, Bob, finally stated the disagreement (lines 16-22). At this point, a negative evaluation of the proposal had been prefigured through several kinds of mitigation - both conversational delays and silences. Even at this point, the disagreement was delayed from early positioning within the turn. Bob started 
with an ambiguous reference to a point made earlier, "just a- again it's a disc- I feel-" (line 16). Since he had voiced concern several times earlier during the meeting about the need to generate more enthusiasm for the team competition, that was most likely the issue he was referring to here. Following this allusion, he finally articulated the disagreement itself (lines 17-22). It was mitigated with hedges and neutrally phrased.

From this turn on, the pace of turn transitions picked up dramatically. Whereas before, multiple silences had seemed to indicate a universal reluctance to speak, participants were now so ready to talk that most of the rest of the turns overlapped with each other. There may have been several reasons for this shift in pacing. First, the delays preceding the disagreement may have partly indexed a general unwillingness to be the one to state it, since negative assessments generate vulnerability not only for the proposer, but also for the evaluator. In addition, participants may have oriented to the articulation of the disagreement as a final clarification of what kind of assessment activity was in progress. Finally, this shift illustrates the preference for mutual alignment which so strongly characterized such meetings: When the task before the group had been one of disagreement, hesitation abounded; once the negative assessment had been stated, all subsequent moves could be constructed as agreements with the assessment.

Thus, at the first potential transition space in the negative assessment, but before Bob had finished talking, Dave began a chorus which echoed the assessment (line 23). Bob ended his negative assessment at the next potential transition space, leaving the floor to Dave, who continued with a somewhat ambiguous phrase about a "review of the first one" (line 24). Possibly he meant that the facilitators could review the idea of inviting whole teams after the first training session. Dave had a tendency to ramble in a free associative kind of way.

At the next potential transition space in Dave's chorus, Beth broke in with a reversal (lines 26-28). The overlap continued for a few more words from Dave; then he ceded the floor to Beth. In her phrasing, "why don't we just inviteteams," Beth managed to convey the impression that this was the view she had held all along. After a brief pause, she added "the first time" (line 28), echoing a phrase from the chorus, "the first one" (line 24). Beth's evident efforts to align herself as fully as possible with the positions articulated by other members of the group displayed her decision to accept, rather than contest, the others' point of view. Bob concluded the sequence by echoing Beth (line 29), and the team moved on to a different topic of conversation.

\section{Conclusion}

In conclusion, I return to the ways in which this research contributes to studies of politeness and talk in the workplace. In the materials I presented, meeting participants' extensive efforts to mitigate their disagreements appeared to represent attempts to reduce the threat to the face of their interlocutors. Similarly, team members' readiness to articulate reversals could be understood as attempts to protect their own face. Brown and Levinson's original politeness model is, thus, pertinent in interpreting these interactions (1987).

The second wave of politeness research, stressing the importance of particular cultures in shaping local practices, also helps illuminate the actions of cross-functional team members. The employees examined here probably resemble Brown and Levinson's 
universalized rational actor "Model Person" as closely as any ethnographic subjects could (since rational actor theory is most often applied to corporate managers). Yet their actions were still inflected by a specific cultural logic linked to the organization of large American corporations. Many Americans who have not spent time in a corporate environment find the lack of directness revealed in example (7), for instance, quite amazing. New employees need to be socialized into such practices (Wasson 1996).

At the same time, the materials presented here also highlight the limitations of the second wave of politeness research. Studies in this vein have tended to assume that cultures constitute homogeneous entities. By contrast, the employees I studied showed considerable variation in their degree of caution. Also, previous studies have often equated the notion of "culture" with values, ignoring questions about the local political economy. Yet the actions of the managers and professionals I observed were crucially shaped by their lived experience in the political field of a large firm.

Of course, already Brown and Levinson were aware that power and cultural difference played an important role in shaping local understandings and practices of politeness. Their formula for the weightiness of a face threatening act included "a measure of the power that H[earer] has over S[peaker]" and a consideration of the "culturally and situationally defined ranking of impositions" (1987: 76-77). However, such questions of context were not a primary focus of their study, and I believe that it is in this area that we can most fruitfully extend their research.

In this paper, therefore, I sought to connect particular interactional phenomena which could be classified as "politeness" - mitigated disagreements, reversals - to the political economy of the context in which they occurred - the corporation - by highlighting key strands in a complex web of organizational practices and structures, and the dispositions of the actors who negotiated them. Thus, at the most immediate level, the interactions of cross-functional team members indexed the ideologies, practices, and opportunities that characterized cross-functional teams. For instance, meeting participants expected to make decisions by consensus. Most of them had little political investment in particular decision outcomes. They had the most to gain from developing friendly relationships with each other.

At the same time, team members' elaborate efforts to downplay disagreement also indexed, in a more complex manner, the logic of the organizational field within which they acted. Their concerns about saying the wrong thing in front of the wrong audience were inculcated by their lived experience in a world in which everyone's success was judged by how quickly one managed to climb the corporate ladder. They had seen colleagues' careers derailed by inadequate caution in speaking out. They knew that reputations could be helped or harmed by the stories that employees constantly circulated about their fellows. Their caution indexed the power of the organization to control the career success of its members, and the power of fellow employees to shape their reputation through gossip.

Since the context for this examination of "polite" interactional practices was a workplace, my findings were also illuminated by the literature on talk at work. In particular, I tried to emulate the close attention to the construction of turns and sequences which characterizes this literature. For instance, I identified the "reversal" as a common type of turn in these meetings. In describing the way participants constructed their negative assessments, I drew on extensive previous research into assessments and mitigated 
disagreements. My discussion of the organization of decision-making activities built on previous analyses of bargaining sequences.

But I also sought to go beyond the immediacies of such interactional structures. Studies of talk in the workplace have tended to focus on participants' enactment of their technical expertise. Such research is valuable but it only highlights half the picture. In practice, employees' activities are shaped by both an occupational logic and an organizational logic. Decisions are made not just on technical grounds but also for political reasons. My focus on corporate employees' caution thus represented an effort to highlight the other half of their life in the workplace.

\section{References}

Agha, Asif (1994) Honorification. Annual Review of Anthropology 23: 277-302.

Balholm, Field and Associates (1992) High commitment high performance team training.

Boden, Deirdre (1994) The business of talk: Organizations in action. Cambridge: Polity Press.

Bourdieu, Pierre (1990) The scholastic point of view. Cultural Anthropology 5.4: 380-391.

Briggs, Charles L. (1997a) Introduction: From the ideal, the ordinary, and the orderly to conflict and violence in pragmatic research. Pragmatics 7.4: 451-459.

Briggs, Charles L. (ed.) (1997b) Special issue on conflict and violence in pragmatic research. Pragmatics 7.4 .

Brown, Penelope, and Stephen C. Levinson (1987) Politeness: Some universals in language use. Cambridge: Cambridge University Press.

Button, Graham (ed.) (1992) Technology in working order: Studies of work, interaction, and technology. London: Routledge.

Caldas-Coulthard, Carmen Rosa, and Malcolm Coulthard (eds.) (1996) Texts and practices: Readings in critical discourse analysis. London: Routledge.

Dalton, Melville (1959) Men who manage. New York: Wiley.

Davidson, Judy (1984) Subsequent versions of invitations, offers, requests, and proposals dealing with potential or actual rejection. In J.M. Atkinson and J. Heritage (eds.), Structures of social action: Studies in conversation analysis. Cambridge: Cambridge University Press.

Drew, Paul, and John Heritage (1992a) Analyzing talk at work: An introduction. In P. Drew and J. Heritage (eds.), Talk at work: Interaction in institutional settings. Cambridge: Cambridge University Press.

Drew, Paul, and John Heritage (eds.) (1992b) Talk at work: Interaction in institutional settings. Cambridge: Cambridge University Press.

Duranti, Alessandro (1992) Intentions, self and responsibility: An essay in Samoan ethnopragmatics. In J.H. Hill and J.T. Irvine (eds.), Responsibility and evidence in oral discourse. Cambridge: Cambridge University Press. 
Eelen, Gino (1999) Politeness and ideology: A critical review. Pragmatics 9.1: 163-173.

Ehlich, Konrad, and Johannes Wagner (eds.) (1995) The discourse of business negotiation. Berlin: Mouton de Gruyter.

Engeström, Yrjö, and David Middleton (eds.) (1996) Cognition and communication at work. Cambridge: Cambridge University Press.

Fairclough, Norman (1989) Language and power. London: Longman.

Firth, Alan (1991) Discourse at work: Negotiating by telex, fax, and phone. Unpublished doctoral dissertation, Department of Language and Intercultural Studies, Aalborg University, Denmark.

Firth, Alan (ed.) (1995) The discourse of negotiation: Studies of language in the workplace . Oxford: Pergamon.

Foucault, Michel (1977) Discipline and punish: The birth of the prison. Translated by Alan Sheridan. New York: Vintage Books.

Foucault, Michel (1980) Power/knowledge: Selected interviews and other writings 1972-1977. Translated by Colin Gordon, Leo Marshall, John Mepham, Kate Sopher. Edited by C. Gordon. New York: Pantheon Books.

Francis, David. (1995) Negotiation, decision-making and formalism: The problem of form and substance in negotiation analysis. In K. Ehlich and J. Wagner (eds.), The discourse of business negotiation. Berlin: Mouton de Gruyter.

Gal, Susan (1989) Language and political economy. Annual Review of Anthropology 18: 345-367.

Gal, Susan, and Kathryn Woolard (eds.) (1995) Special issue on constructing languages and publics. Pragmatics 5.2.

Goffman, Erving (1959) The presentation of self in everyday life. New York: Anchor Books.

Goodwin, Charles (1986) Between and within: Alternative sequential treatments of continuers and assessments. Human Studies 9: 205-217.

Goodwin, Charles, and Marjorie Harness Goodwin (1992) Assessments and the construction of context. In A. Duranti and C. Goodwin (eds.), Rethinking context: Language as an interactive phenomenon. Cambridge: Cambridge University Press.

Goodwin, Marjorie Harness (1982) Processes of dispute management among urban black children. American Ethnologist 9: 76-96.

Goodwin, Marjorie Harness (1983) Aggravated correction and disagreement in children's conversations. Journal of Pragmatics 7: 657-677.

Goodwin, Marjorie Harness (1990) He-said-she-said: Talk as social organization among black children. Bloomington: Indiana University Press.

Hill, Jane H., and Judith T. Irvine (1992) Introduction. In J.H. Hill and J.T. Irvine (eds.), Responsibility and evidence in oral discourse. Cambridge: Cambridge University Press.

Jackall, Robert (1988) Moral mazes: The world of corporate managers. Oxford: Oxford University Press. 
Jefferson, Gail, Harvey Sacks, and Emanuel A. Schegloff (1987) Notes on laughter in the pursuit of intimacy. In G. Button and J.R.E. Lee (eds.), Talk and social organisation. Clevedon: Multilingual Matters.

Kangasharju, Helena (1996) Aligning as a team in multiparty conversation. Journal of Pragmatics 26: 291319.

Kanter, Rosabeth Moss (1977) Men and women of the corporation. New York: Basic Books.

Kienpointner, Manfred (ed.) (1999) Special issue on ideologies of politeness. Pragmatics 9.1.

Kroskrity, Paul, Bambi Schieffelin, and Kathryn Woolard (eds.) (1992) Special issue on language ideologies. Pragmatics 2.3.

Kunda, Gideon (1992) Engineering culture: Control and commitment in a high-tech corporation Philadelphia: Temple University Press.

Lerner, Gene H. (1993) Collectivities in action: Establishing the relevance of conjoined participation in conversation. Text 13.2: 213-245.

Mao, Lu Ming Robert (1994) Beyond politeness theory: 'Face' revisited and renewed. Journal of Pragmatics 21: $451-486$.

Maynard, Douglas W. (1984) Inside plea bargaining: The language ofnegotiation. New York: Plenum Press.

Miller, Laura (1989) The Japanese language and honorific speech: Is there a Nihongo without keigo? Penn Linguistics Review 13: 38-46.

Mills, C. Wright (1951) White collar. New York: Oxford University Press.

Okamoto, Shigeko (1999) Situated politeness: Coordinating honorific and non-honorific expressions in Japanese conversations. Pragmatics 9.1: 51-74.

Ourousoff, Alexandra (1993) Illusions of rationality: False premises of the liberal tradition. Man 28: 281-298.

Pomerantz, Anita (1984) Agreeing and disagreeing with assessments: Some features of preferred/dispreferred turn shapes. In J.M. Atkinson and J. Heritage (eds.), Structures of social action: Studies in conversation analysis. Cambridge: Cambridge University Press.

Riesman, David (1950) The lonely crowd: A study of the changing American character. New Haven: Yale University Press.

Rosenbaum, James E. (1984) Career mobility in a corporate hierarchy. Orlando: Academic Press.

Sacks, Harvey (1987) On the preferences for agreement and contiguity in sequences in conversation. In G. Button and J.R.E. Lee (eds.), Talk and social organisation. Clevedon: Multilingual Matters.

Sacks, Harvey, Emanuel A. Schegloff, and Gail Jefferson (1974) A simplest systematics for the organization of turn-taking for conversation. Language 50: 696-735.

Sarangi, Srikant, and Celia Roberts (1999a) The dynamics of interactional and institutional orders in workrelated settings. In S. Sarangi and C. Roberts (eds.), Talk, work and institutional order: Discourse in medical, mediation and management settings. Berlin: Mouton de Gruyter.

Sarangi, Srikant, and Celia Roberts (eds.) (1999b) Talk, work and institutional order: Discourse in medical, mediation and management settings. Berlin: Mouton de Gruyter. 
Schegloff, Emanuel A. (1995) Parties and talking together: Two ways in which numbers are significant for talk-in-interaction. In P. Ten Have and G. Psathas (eds.), Situated order: Studies in the social organization of talk and embodied activities. Washington: University Press of America.

Schegloff, Emanuel A., Gail Jefferson, and Harvey Sacks (1977) The preference for self-correction in the organization of repair in conversation. Language 53: 361-382.

Schieffelin, Bambi, Kathryn A. Woolard, and Paul Kroskrity (eds.) (1998) Language ideologies: Practice and theory. New York: Oxford University Press.

Schiffrin, Deborah (1984) Jewish argument as sociability. Language in Society 13: 311-335.

Schwartzman, Helen (1989) The meeting: Gatherings in organizations and communities. New York: Plenum Press.

Silverstein, Michael (1998) Contemporary transformations of local linguistic communities. Annual Review of Anthropology 27: 401-426.

Wasson, Christina (1996) "Your candor would be appreciated": Performing contradictory identities in business meetings. Paper read at Discourse as Mosaic: Linguistic Re/Production of Identities and Ideologies, at Washington, DC.

Wasson, Christina (1998) "Feeding the gorilla": Meetings, work and hierarchy in corporate America. Paper read at American Anthropological Association Annual Meeting, December 4, Philadelphia.

Wasson, Christina (2000) "Feeding the gorilla": Talk and surveillance in business meetings. Paper read at 4th International Conference on Organizational Discourse, July 28, London.

Watts, Richard J. (1992) Linguistic politeness and politic verbal behavior: Reconsidering claims for universality. In R.J. Watts, S. Ide and K. Ehlich (eds.), Politeness in language: Studies in its history, theory, and practice. New York: Mouton de Gruyter.

Watts, Richard J. (1999) Language and politeness in early eighteenth century Britain. Pragmatics 9.1: 5-20.

Watts, Richard J., Sachiko Ide, and Konrad Ehlich (eds.) (1992) Politeness in language: Studies in its history, theory, and practice. New York: Mouton de Gruyter.

Whyte, William H. (1956) The organization man. New York: Simon and Schuster.

Wodak, Ruth (ed.) (1989) Language, power, and ideology: Studies in political discourse. Amsterdam: John Benjamins Publishing Company.

Woolard, Kathryn, and Bambi Schieffelin (1994) Language ideology. Annual Review of Anthropology 23: 55-82. 